\title{
Properties and bending behavior of Nickel coated Mild steel sheet during
} air bending

\author{
P.Padmanabhan ${ }^{1}$, D.Pritima ${ }^{2}$ and M.Ravichandran ${ }^{3}$ \\ ${ }^{1}$ Department of Mechanical Engineering, V V College of Engineering, \\ Tisaiyanvilai-627657, Tamil Nadu, India. \\ ${ }^{2}$ Department of Mechanical Engineering, Vickram College of Engineering, \\ Sivagangai - 630561, Tamil Nadu, India. \\ ${ }^{3}$ Department of Mechanical Engineering, Chendhuran College of Engineering and Technology, \\ Pudukkottai-622507, Tamil Nadu, India. \\ $2^{*}$ Corresponding Author Mail: pritimadavid82@gmail.com
}

\begin{abstract}
Springback refers to the elastic recovery which subject to a geometrical change when the metal undergoes deformation during the forming process. The experimental investigation of this paper is focused to analyze the behavior of spring back of nickel coated mild steel (NCMS) sheets during the air bending process. The hardeness and surface roughness was measured after coating. Experimental investigation have been conducted to resolve the influence of control parameters such as Orientations $(\theta)$, Width of the sheet $(\mathrm{Ws})$, Punch travel $(\mathrm{Tp})$, Holding time $(\mathrm{Ht})$ and Punch Velocity (v) on spring back behavior. As a results, the incraese in Orientations, Width of the sheet, Punch travel andd Punch Velocity incraese the springback angle.
\end{abstract}

Keywords: Mild steel, Nickel Coating, Electroplating, Springback, Air bending,

\section{INTRODUCTION}

Bending of sheet metal is the most prevalent and needed process in the production industry. This forming process of sheet metal has wide application in the areas of aerospace, architectural, medical, telecommunication, defence and electronics. Bending process is the most productive and powerful process which satisfies the customer demands of greater accuracy in a very minimum formation time. At this scenario, Air bending is the most preferred one when it is compared with v-die bending [1]. In Air bending same set of tools are used for achieving the various bend angles which gives a significant asset in terms of geometry and permanence. In aerospace and architectural side, the mechanical property namely corrosion plays a vital role which permits the gradual destruction of the appearance due to the effect of chemical reaction with the environment. So the use of coated sheet comes to prevalence and it is in great demand.

This paper shows the usage of nickel coated steel sheet because of its higher corrosion resistance, heat resistance and it also has attractive surface finish. The assessment of forming process is the most essential one in the case of structural items and skin panels in aerospace industry. Sheet formability is evaluated by many factors in which the shape fixability plays an important role. Spring back plays a vital role in manufacturing process. It is typical and necessary in all the phases of the production process in which the material undergoes dimensional changes. The mechanical and functional characteristics which decides the formability and failure behaviour of the material are analyzed for coated and laminated sheets [2]. In the bending process, the load is applied on the sheet metal, as a result the metal is bent to the required shape. Due to the elastic recovery, the whole strain on the work piece is reduced after the removal of load. Details about springback is significant for a designer in order to give recompense for spring back in die design for an accurate product and ease of assembly. The control of springback is essential since air bending is primary sheet bending process engaged in most of the manufacturing of structural products. In the past years lot of research and analysis on springback have been done and few vital investigations are reviewed.

The effect of various control parameters such as coating thickness, orientation of the sheet, punch radius, die radius, die opening, punch velocity, and punch travel were studied on the springback behaviour of electrogalvanised steel sheets during air bending process which also emphasized that increase in above parameters increases springback [3]. $A$ lubricant namely white grease is helpful to reduce the springback of interstitial steel sheet during air bending process [4].The orientation of the material anistrophy which results in the variation of the springback was investigated by both numerical and experimental investigations in high strength steels [5]. The influence of springback of aluminium 6063 alloy after heat treatment in air bending process was studied [6]. The artificial neural network was productively used to determine the springback [7] . in which Various regression models like linear, linear-square, linear interaction and quadratic terms were employed for the prediction of springback and found that quadratic model is more accurate in springback prediction. The effects of springback are reduced after forming by response surface method [8 ].. Finite element analysis was used to predict the influence of anisotropy on springback of Numisheet-2005 since better formability is achieved when anisotropy increases[9].The full factorial and analysis of variance methods in design of experiments shows that die and punch radii are the most dominant parameters which influence the springback of stainless steel sheets in $\mathrm{V}$ die free bending process[10]. The influence of the process parameters combinations like die radius and clearance are examined with the help of Response surface methodology[11].The combination of explicit Finite element simulation with physical experiments put forth the clear understanding of friction behaviour on rotary draw bending of thin walled tube under different surface conditions [12].The process parameter namely punch travel is the most influencing parameter to determine the bend force of interstitial free steel sheet was determined by applying response surface methodology [13].

Mild steel is used for the various applications because of its low cost and availabilty. Nickel coating on steel and copper alloys were analysed and its effect on springback was investigated and was finally concluded that 
springback was significantly influenced by coating thickness [14]. So it is very important to select a suitable coating material which has the desirable properties which also do not react with the environment. It was also noted that the springback relys on the material properites such as yield strngth, young's modulus, strain hardening exponent and plastic strain ratio [15]. New springback graphics of aluminium and stainless steel sheets were obtained which also enlarges the data in order to design the bending dies [16]. Numerous investigations on sheet metal bending shows that the springback behaviour was influenced by the control parameters like punch radius, die radius, die opening and punch velocity[17]. Finite Element Analysis along with Taguchi method and analysis of variance was used to find the influence of control parameters on sheet metal in order to reduce the amount of springback [18]. A theoretical model was presented and validation of the model was done to determine the springback of thin bent sheets [19].An artificial neural network approach is used to develop a model to estimate the amount of springback and bend force in electrogalvanised steel sheets [20]. The study of the effect of the area of the holes, die angles, die widths and punch radius on the value of the spring-back and the bending forces of perforated carbon steel material is studied in V-die bending [21].

From the above literatures, unfortunately only very few details are there on the forming and springback behaviour of coated steel sheets. Hence the present paper aims to analyse the springback behaviour of nickel coated steel sheets. So the parameters considered in this paper are orientation of the sheet, width of the sheet, punch travel , holding time and punch velocity.

\section{EXPERIMENTAL SET UP}

The sheet metals chosen for the experiment are mild steel and nickel coated mild steel. The tensile test was conducted to determine the mechanical properties of both the sheets. The comparison of material properties before and after coating of sheets were shown in the Table 1 . Mild steel plate is coated with the nickel by using the electro plating process and then the plate is cut in to the required dimensions. The thickness of the nickel coated sheet is $0.68 \mathrm{~mm}$. The specimens for the experiment are prepared from the coated and uncoated steel sheets to a constant length size of $120 \mathrm{~mm}$. The widths of the specimens are $30 \mathrm{~mm}, 40 \mathrm{~mm}, 50 \mathrm{~mm}, 60 \mathrm{~mm}$ and $70 \mathrm{~mm}$. The sheet orientations were $0^{\circ}, 22.5^{\circ}$, $45^{\circ}, 67.5^{\circ}$ and $90^{\circ}$. The experiments were conducted in universal testing machine (UTM) with 400KN capacity as shown in the figure. The tooling setup includes a die and punch made of hardened steel. The punch was mounted in the upper arm of UTM and the die was placed on the lower platform. The sheet blanks were positioned properly in between punch and die. The required depth for bending sheet is achieved by the punch travel. When the sheet is bent, and the punch is still in its maximum position, ink is applied on the profile of the bent sheet and the ink impression of the profile is obtained on a piece of white sheet, supported by a thermo coal pad. When the punch is removed from the sheet, the ink impression of the profile of sheet is obtained in the similar fashion. The angles of the ink impressions are measured and the difference between these two angles gives the spring back for that particular sheet. The digitized images were imported to CAD software and the necessary bend angles were measured using CAD software. The difference between bend angle during loading and after unloading gives the spring back angle. The bend force was measured by the digital display of load cell arrangement. The sheets were bent to different depths such as $5,10,15,20$ and 25 mm by controlling punch travel. The tooling geometries and process parameters are shown in Table 2. Experiments were conducted with a combination of parameters, and the tooling geometries.

Table 1. Comparison of material properties before and after coating of sheet

\begin{tabular}{|l|l|l|}
\hline Material property & MS sheet & NCMS sheet \\
\hline Young's modulus (GPa) & 208 & 220 \\
\hline Yield Strength (MPa) & 172 & 190 \\
\hline Poisson's Ratio & 0.3 & 0.322 \\
\hline Melting point $\left({ }^{\circ} \mathrm{C}\right)$ & 1538 & 1620 \\
\hline Density $\left(\mathrm{g} / \mathrm{cm}^{3}\right)$ & 7.85 & 8.9 \\
\hline
\end{tabular}

Table 2. Tooling geometries and process parameters

\begin{tabular}{|l|l|}
\hline Die opening,$W_{\mathrm{d}}$ in $(\mathrm{mm})$ & 60 \\
\hline Die radius,$R_{\mathrm{d}}$ in $(\mathrm{mm})$ & 6 \\
\hline Punch travel,$d_{\mathrm{p}}$ in $(\mathrm{mm})$ & $5,10,15,20,25$ \\
\hline Punch radius,$R_{\mathrm{p}}$ in $(\mathrm{mm})$ & 16 \\
\hline Coating thickness,$t_{\mathrm{c}}$ in $(\mathrm{mm})$ & 0.02 \\
\hline Width of the sheets,$W_{\mathrm{s}}$ in $(\mathrm{mm})$ & $30,40,50,60,70$ \\
\hline Thickness of the sheets,$T$ in $(\mathrm{mm})$ & 0.62 \\
\hline Length of the sheets,$L_{\mathrm{s}}$ in $(\mathrm{mm})$ & 120 \\
\hline Orientations of the sheets, $\theta$ in (degrees) & $0^{\circ}, 22.5^{\circ}, 45^{\circ}, 67.5^{\circ}, 90^{\circ}$ \\
\hline
\end{tabular}




\section{RESULTS AND DISCUSSION}

Spring back angles are measured accurately from experiments conducted with a combination of control variables such as orientation of the sheet, strain hardening exponent, width of the sheet, punch travel, holding time and punch velocity. The nickel coated mild steel plates were analysed according to the variation in angles and depth. The direct effects of various parameters on spring back are explored through graphs.

\subsection{Hardness and surface roughness test}

The experiments were carried out with 2 sets of specimen, one based on mild steel and other based on nickel coated mild steel sheet. The hardness of the plain MS was found to be $63 \mathrm{HV}$. The hardness for the Nickel Coated MS specimen was increased to $75 \mathrm{HV}$. This indicates that the nickel coating increases the hardness of the substrate at surface level. The variation of hardness for the two specimens is shown in the Fig. 1. The improved hardness is observed for the coated MS. The variation of surface roughness for coated and uncoated steel sheets are shown in Fig. 2 . It was also found that uncoated MS specimens have large variation in roughness when compared to nickel coated MS specimens. Hence, it is implicit that coated process can improve the surface quality of the substrate.

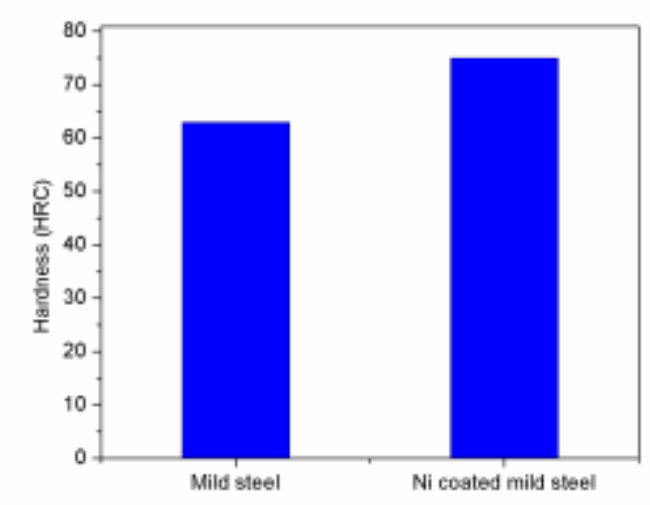

Fig1: Variation of hardness for MS and NCMS

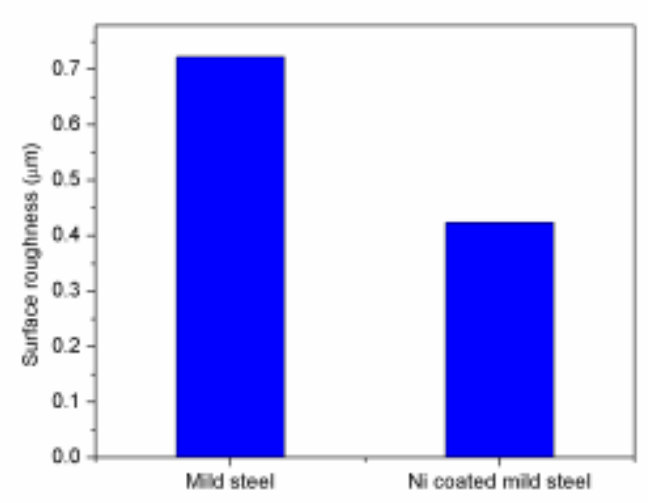

Fig 2: Variation of Surface Roughness for MS and NCMS

\subsection{Effect of Orientation on springback}

The spring back angles for uncoated and coated steels in both $0^{\circ}$ and $90^{\circ}$ orientations and their effects are shown in the fig. 3. It is noted that the orientation has a great influence on spring back for both uncoated and coated sheets and the work blank along the $90^{\circ}$ orientation exhibits greater spring back than the blank of $0^{\circ}$ orientation. It is understood that the spring back angle is a function of yield strength to modulus of elasticity ratio $(\sigma$ y /E) [13] which is higher for transverse direction than rolling direction.

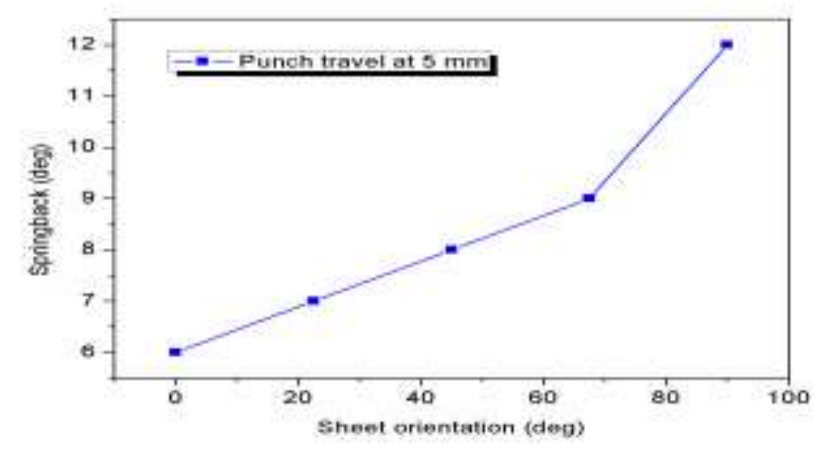

Fig 3: Effect of Orientation angle on spring back

\subsection{Effect of Width on spring back}

The Fig. 4 shows the spring back angle for different widths of the sheet. It is very clear that the spring back increases as the width increases. The springback depends on the strength of the materials. If the sheet width increases the force required to bend the sheet is also increased. Thus the increase in springback is attained after releasing the load. The maximum springback angle is obtained for the sheet width of $70 \mathrm{~mm}$ for the punch travel of $5 \mathrm{~mm}$. 


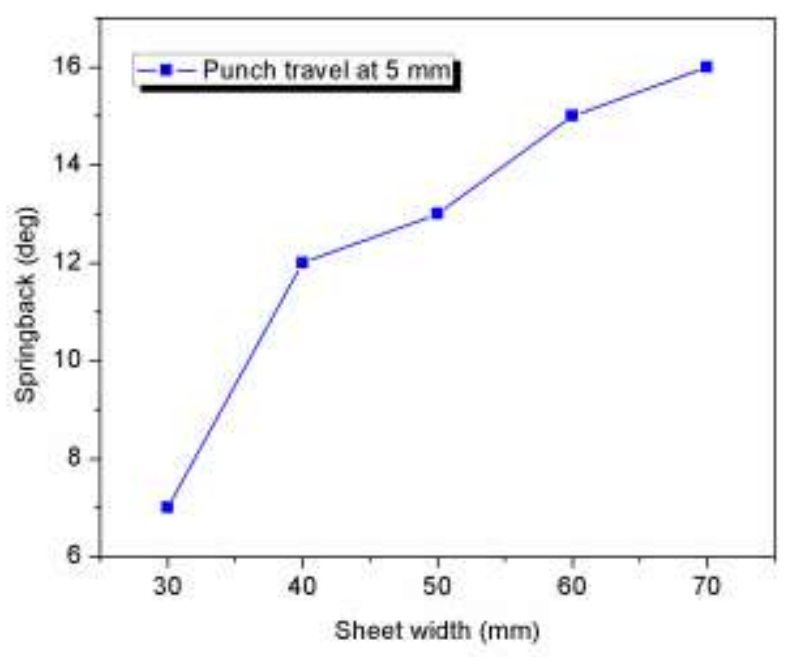

Fig 4: Effect of sheet width on spring back

\subsection{Effect of Velocity on springback}

The effect of punch velocity on spring back is shown in Fig. 5. Springback increases with an increase in punch velocity. The reason may be the variation of friction coefficient with sliding velocity of the sheet which is proportional to the punch velocity. The values of the friction coefficient decrease due to the increase of the sliding velocity [12]. Since the decrease in coefficient of friction reduces the friction, the spring back increases. The coefficient of friction declines with increasing some field parameter, which depends on the product of coated sheets. The springback value for Electro galvanised sheet is greater when compared to that for the uncoated sheet. It was observed that the effect of velocity on spring back is more dominant in EG steel than in uncoated sheet [3].

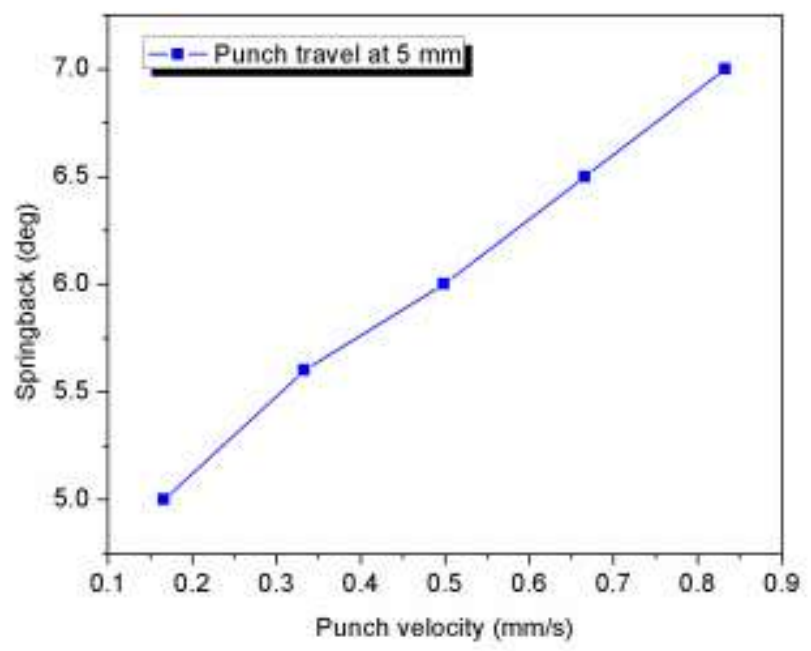

Fig 5: Effect of punch velocity on springback

\subsection{Effect of holding time on springback}

The effect of holding time on the spring back is indicated in Fig. 6. The spring back decreases when the holding time increses and the holding time are maximum when the spring back low. The reason for this is due to the increse in permanent deformation for the increse in holding time and thus the decrease in springbcak is achieved during air bending of nickel coated mild steel sheets. 


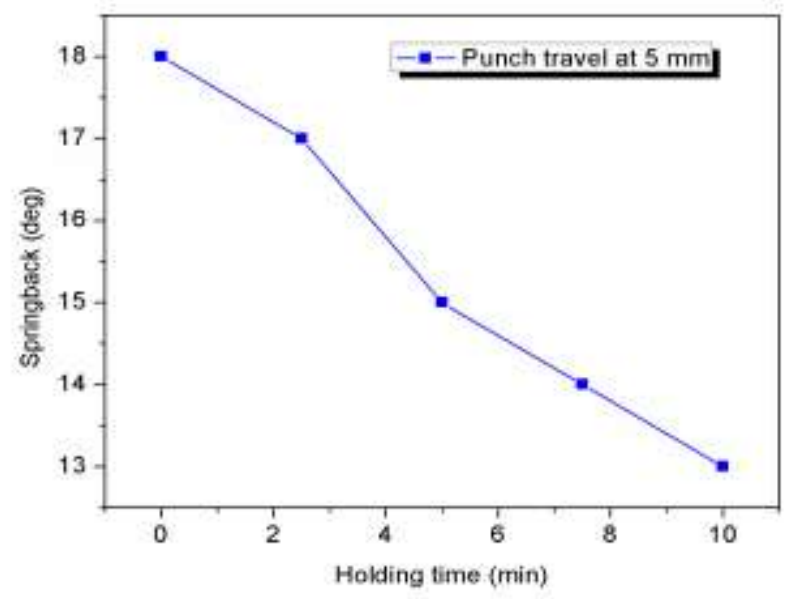

Fig 6: Effect of holding time on springback

\subsection{Effect of nickel coating on spring back}

The effect of nickel coating on springback is shown in the Fig. 7 . It is evident that the spring back angle increases with increasing punch travel. It also shows that the spring back angle increases for the coated MS for the same punch travel. This can be related to the frictional properties of the coating. The nickel coating further reduces the coefficient of friction [2] thereby lowering the friction, and hence the spring back angle is found to increase.

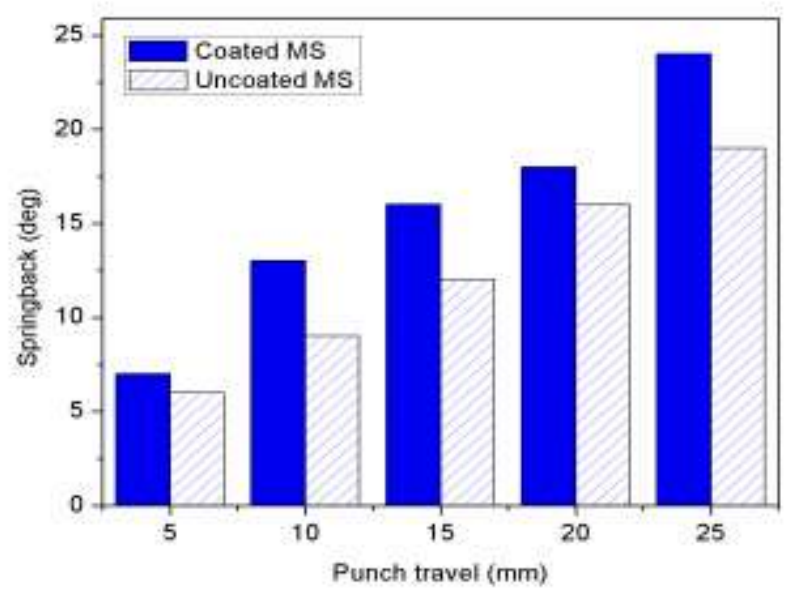

Fig 7: Effect of nickel coating on springback

\section{CONCLUSION}

The experimental work has been performed on the nickel coated sheets and the following conclusions have been arrived.

- The experimental setup namely fabrication of punch and die, preparation of sheets with nickel plating and shearing of sheets with different orientation were done.

- The nickel coating increases the hardness of the substrate at surface level. The effect of surface roughness values are measured, the uncoated MS specimens have large variation in roughness when compared to nickel coated MS specimens and the coated process can improve the surface quality of the substrate.

- The effect of various parameters namely orientations, width of the sheets, punch travel, holding time and Velocity on the spring back are experimentally analysed.

- The experimental results of the punch travel, velocity, and width of the sheets increased which increases the spring back. The holding time increases when the spring back decreases.

- The spring back is inversely proportional to the holding time and the spring back is directly proportional to the width of the sheets. The velocity gets decreased when the spring back decreases. 


\section{REFERENCES}

1. Wang , J., Gau , J.T. 2008. Springback control of sheet metal air bending process.J Manuf Process.10, 21-27 .

2. Kim, J.K., Yu, T.X. 1997. Forming and failure behaviour of coated laminated and sandwiched sheet metals: a review. J.Mater.Process.Technol. 63, 33-42.

3.Vasudevan, D., Srinivasan, R., Padmanabhan, P. 2011. Effect of process parameters on springback behaviour during air bending of electrogalvanised steel sheet. P. J. Zhejiang Univ. Sci. A .12,183 - 189.

4. Narayanasamy ,R. ,Padmanabhan ,P .2010.Influence of Lubrication on Springback in Air Bending Process of Interstitial Free Steel Sheet.J.Mater.Eng.Perform .19,246-251.

5. Gomes,C., Onipede,O., Lovel,M. 2005. Investigation of springback in high strength anisotropic steels. J.Mater.Process.Technol.159, 91-98.

6. Kumar, S., Sardana,D., Rajpara,M.P., Patel,S.S. 2015. Study of Springback Analysis in air bending process after different heat treatment of aluminium 6063 alloy. Int. J. Adv. Res. Sci. Engg.4,1880 - 1887.

7. Darendeliler.H. 2014. Springback analysis in air bending process through experiment based artificial neural networks. Procedia Eng.81, 999 - 1004.

8. Naceur,H., Guo Y.Q., Elechi,S.B. 2006. Response surface methodology for design of sheet forming parameters to control springback effects. Comput Struct . 84, 1651-1663.

9.Verma, R.K., Haldar, A. 2007. Effect of normal anisotropy on spring back. J.Mater.Process.Technol.190, $300-304$.

10. Buang, M.S., Abdullah ,S.A., Saedon ,J. 2015 . Effect of die and punch radius on spring back of stainless steel sheet metal in the air V- die bending process. J MECH ENG SCI. 8, 1322-1331.

11. Mkaddem,A., Saidane,D. 2007. Experimental approach and RSM procedure on the examination of springback in wiping - die bending processes . J.Mater.Process.Technol.189, 325-333.

12. Yang, H. , Li ,H., Zhan ,M. 2010.'Friction role in bending behaviors of thin - walled tube in rotary - draw-bending under small bending radi. J.Mater. Process. Technol. 210, 2273-2284.

13. Narayanasamy , R. , Padmanabhan ,P .2009. Application of response surface methodology for predicting bend force during air bending process in interstitial free steel sheet. INT J ADV MANUF TECH. 44,38 - 48.

14. Ravichandran,M., Saravanan,S., Balasubramaniyan, V.2010. Investigations on erosion and corrosion behavior of high velocity oxy fuel sprayed WC-Cr3C2-Ni Coatings on AISI 1018 Steel. HTM J. Heat Treatm. Mat.71,163-169.

15. Gotzinger, M., Kalyanasundaram,S., Hodgson, P., Hall, M. C., Hodgson. P, 2001.

A methodology for springback prediction. SAE Transactions. 110, 1181-1186.

16. Romeu M.L., Ciurana, J., Ferrer, I. 2007.Springback determination of sheet metals in air bending process based on experimental work. J.Mater. Process. Technol. 191,174-177.

17. Bahloul, R., Elechi, S.B., Potiron, A. 2006.Optimisation of springback predicted by experimental and numerical approach by using response surface methodology. J.Mater. Process. Technol. 173,101-110.

18. Sachin, S., Chaudhari , Patil,K. 2015.Springback prediction of sheet metal in deep drawing process. Int. J. Mech. Engg. Tech. 6, 09-17.

19 .Braga, M.T., Filho, L.A., Menezes, M.A. 2010. Springback analysis of thin bent sheets on elastomeric die. Int. J. Mater. Form. 3, 1075-1078.

20. Srinivasan, R., Vasudevan, D., Padmanabhan ,P . 2014.Prediction of spring-back and bend force in air bending of electro-galvanised steel sheets using artificial neural networks. Aust. J. Mech. Eng.12,25 - 37.

21.Farsi,M.A., Arezoo,B. 2011.Bending force and spring-back in v-die-bending of perforated sheet-metal components. J. Braz. Soc. Mech. Sci. \& Eng.33, $45-51$.

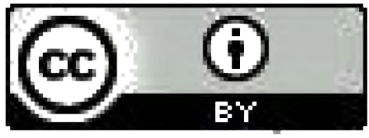

This work is licensed under a Creative Commons Attribution 4.0 International License. 